\title{
Geomechanical conditions of vein gold de- posits in permafrost zone
}

\author{
Arkady Avdeev ${ }^{* 1}$, Elena Sosnovskaya ${ }^{1}$ \\ ${ }^{1}$ Institute of Mining of the Ural Branch of the Russian Academy of Sciences; - 620075. \\ Ekaterinburg, Russia
}

\begin{abstract}
Developing the vein deposits in the permafrost zone results in specific geomechanical conditions. The paper describes the main results of studies of the geomechanical conditions of 8 vein deposits located in the permafrost zone for 2000-2020. In the process of research, zoning of the temperature conditions in mines has been carried out. The research has established the position of the permafrost zones, the natural transition zones of frozen rocks to thawed rocks, the zones of seasonal ventilation thawing and technogenic thawing. The authors have made the qualitative assessment of the degree of stability of the mine workings and pillars, taking into account the temperature conditions. It is proposed, when evaluating the stability of structural elements of geotechnologies, to adjust the strength properties of rocks using a differentiated coefficient of structural weakening. The paper has presented the results of field measurements of the initial stress-deformed state at various temperature conditions. The general regularities of the distribution of initial stresses are established: hydrostatic stresses act in frozen rocks, and increased gravitational-tectonic stresses act in natural and technogenic thawed rocks. The authors have proposed to use the obtained results as boundary conditions for the calculation of geotechnological parameters in the design and initial development of vein gold deposits of the permafrost zone. The authors have proposed the measures to improve the safety of mining operations in permafrost: thermal insulation of mine walls, use of electric transport, regulation of ventilation.
\end{abstract}

\section{Introduction}

Two thirds of gold deposits in Eastern Siberia and North-East Russia are found in permafrost conditions. The maximum depth of the frozen rock mass can reach 400-500 m. Permafrost rock mass is nonuniform by temperature conditions, thickness, ice presence and composition. To substantiate the optimal parameters of underground geotechnologies, it is necessary to objectively consider the properties of the cryolithic zone, which requires a detailed study of the multifactor influence of perennial permafrost on mining processes. Such studies have been conducted in our country since the mid-20th century by a number of researchers (V.P.Bakakin, A.F.Zilberdbord, Yu.D.Dyadkin, S.V.Potemkin, P.D.Chaban, N.I.Popov, A.E.Sleptsov, V.Yu.Izakson, V.G.Greenev and many others). At present, these studies are still relevant. Cryological characteristics significantly affect the geomechanical

*avdeev0706@mail.ru 
conditions of mines $[1,2]$. Permafrost should be taken into account when engineering calculations of structural elements of development systems, parameters of fastening and backfill [3-6].

To justify the optimal parameters of underground geotechnologies, it is necessary to objectively consider the properties of the permafrost zone, which requires a detailed study of the multifactorial influence of permafrost on mining processes.

The authors carried out long-term studies of the geomechanical condition of permafrost rock masses of 8 vein gold deposits located in the permafrost zone: Irokinda, Kedrovskoye, Mayskoye, Novo-Shirokinskoye, Konevinskoye, Karalveem. The deposits are located in different regions of Eastern Siberia and North-East Russia: in the Patom upland, Chukot mountain area, Eastern Sayan Mountains and Transbaikal. The mines develop steep and inclined gold veins of small and medium thickness (up to $3 \mathrm{~m}$ ). The thickness of the layer of permafrost rock masses varies widely from 150 to $500 \mathrm{~m}$.

The vein gold deposits, in addition to the permafrost zone, have a number of specific mining and geological aspects that determine the choice of underground geotechnology. Gold veins vary widely by thickness: there are both centimetre-long pinches and multimetre-long swells. The dip of veins, in one deposit, can vary from subvertical to shallow. The tectonics of rock masses usually has a complex structure, being characterizes by a large number of cracks, shear zones, ruptured zones. In terms of stability, the peripheral rock mass can vary significantly even within a single mine working. Such difficult mining and geological conditions result in a great variety of mining systems used. In more stable rocks the systems with open stoping zone (solid, chamber-and-pillar, shrinkage) are used, in unstable rocks the additional fastening elements are introduced, and backfilling works are performed. Most of the technologies used, especially in the veins of small and medium thickness, are characterized by low level of mechanization and high labor intensity.

\section{Methods of study}

In the process of study the authors have used a complex of methods, including scientific analysis and generalization of the accumulated experience, field measurements of air temperature and rock mass followed by their mapping [7]; laboratory tests of physical and mechanical properties of rocks [8], evaluation of the initial stress field of rock mass by field measurements of the slot unloading according to the methodology of the Institute of Mining of the Ural Branch of the Russian Academy of Sciences [9]. Based on the results of field measurements, the distribution structure of initial stresses in the cryolithic zone was analyzed, in particular, the average ratios between horizontal and vertical stresses were determined, gravitational and tectonic components of in-situ stresses were estimated.

Vertical $(\sigma \mathrm{v})$, horizontal longitudinal, oriented horizontally along the strike of veins $(\sigma \mathrm{l})$ and transverse, oriented horizontally across the strike of veins ( $\sigma \operatorname{tr})$ are divided into gravitational and tectonic components on the basis of known engineering dependencies [9]:

$$
\sigma_{v}=\sigma_{v}^{g r}+\sigma_{v}^{t}=-\gamma H+\sigma_{v}^{t} ; \sigma_{l}=\sigma_{l}^{g r}+\sigma_{l}^{t}=-\frac{\mu}{1-\mu} \gamma H+\sigma_{l}^{t}, \sigma_{t r}=\sigma_{t r}^{g r}+\sigma_{t r}^{t}=-\frac{\mu}{1-\mu} \gamma H+\sigma_{t r}^{t},
$$

where $\sigma_{v}^{g r}, \sigma_{l}^{g r}, \sigma_{t r}^{g r}$ are gravitational vertical, horizontal longitudinal and transverse initial stresses by A.N.Dinnik, MPa; $\sigma_{v}^{t}, \sigma_{l}^{t}, \sigma_{t r}^{t}$ are tectonic longitudinal and transverse initial stresses, $\mathrm{MPa} ; \mu$ is Poisson's coefficient; $\gamma$ is rock volume weight, $\mathrm{MN} / \mathrm{m}^{3}, \mathrm{H}$ is mining depth, m. 


\section{Study Results}

\section{Temperature conditions of the mine field}

Temperature of air and rock mass during winter and summer periods were measured at the mines under study. The analysis of measurement results has allowed to establish that the permafrost zone is not uniform by temperature conditions in the mine field, and the degree of stability of structural elements of development systems qualitatively depends on the temperature in the peripheral rock mass. In the course of exploitation of the deposit located in the permafrost zone, several areas (zones) with significant differences in temperature conditions and stability of the rock mass are distinguished (Figure).

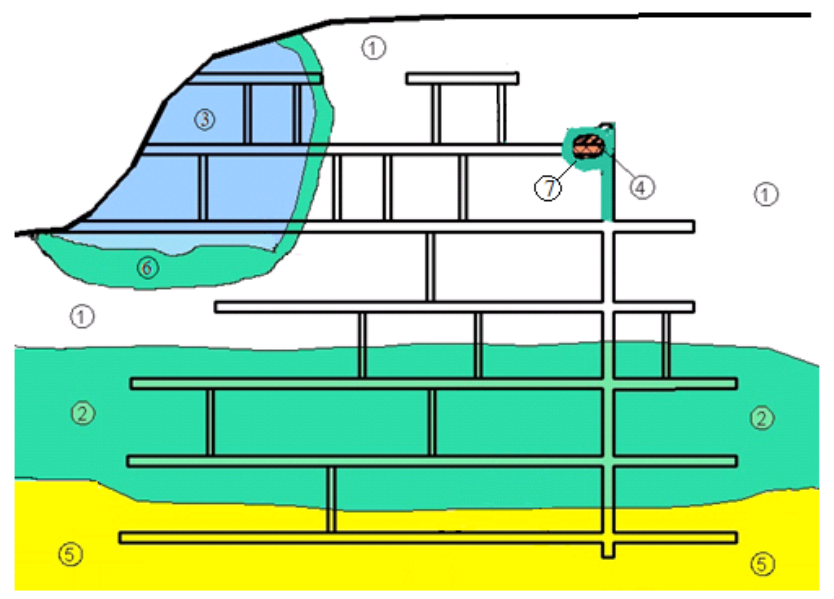

Fig. 1. Scheme of temperature zoning in the mine field

1 - permafrost zone, 2 - natural transition zone of frozen rocks to thawed rocks, 3 - zone of seasonal thawing, 4 - zone of technogenic thawing, 5 - zone of permanently thawed rocks, 6 - "bufferseasonal" zone, 7 - "buffer-technogenic" zone.

First, three areas arising from natural causes are distinguished. This is a permafrost zone itself, extending to a depth down to the isotherm of $-1{ }^{\circ} \mathrm{C}$. Here, the stability of rock outcrops is maximum possible for specific geological and mining and technical conditions. Deeper than the first zone, there is a natural transition zone of frozen rocks into thawed rocks (isotherms $-1 \ldots+0.5^{\circ} \mathrm{C}$ ). Here, under a complex increase in temperature and rock pressure, there is a phase transition of ice filling the cracks in the rocks into water. The rocks are beginning to lose stability and degrade. Destruction processes are intensified in the form of dumps in the presence of ice layers and foliation. The size of this zone in the mine field is quite significant in relation to the scale of mining operations, and is equal about 150-200 m. Deeper than the natural transition zone, there is a deep zone of thawed rocks, whose upper boundary runs along the isotherm of $+0.5^{\circ} \mathrm{C}$. Here the stability of the peripheral rock mass does not depend on permafrost and is fully determined by other geomechanical factors: strength of rocks, watering, cracking, tectonic stresses.

Apart from natural factors, the temperature conditions of the mine are affected by production and technological activities. For anthropogenic reasons, additional areas of permafrost rock thawing occur in the mine field. One of them, the "seasonal" thawing zone, is associated with warm air entering the mine in summer and cold air in winter. The zone extends deep into the mine field at a distance of 150-200 $\mathrm{m}$ from the mouth of the opening workings. Here the stability of rocks in winter is higher than in summer, but with each 
change of seasons the overall stability decreases due to the processes of "freeze-thaw" cycle of ice in the cracks.

Another "technogenic" zone is formed in the form of local areas of thawing the peripheral rock mass. When thawing the mine workings due to technological causes the previously stable mine workings and pillars lose the stable condition and degrade. Such processes were observed, for example, at the Irokinda mine when self-propelled equipment was put into operation instead of electric transport [10]. The depth of wall and mine roof thawing zone is $0.1-2 \mathrm{~m}$. The sizes of the technogenic thawing zone are limited by scales of application of the mining equipment: the stationary electric equipment has the least influence, and the mobile self-propelled transport with internal combustion engines has the greatest influence.

It should be noted that around the areas of anthropogenic thawing it is possible to form buffer transition zones with temperature of $-1 \ldots+0.5^{\circ} \mathrm{C}$, similar to the natural transition zone. But their sizes are usually small (maximum $30 \mathrm{~m}$ near the "seasonal" zone) and the presence of such areas does not significantly distort the overall picture of geomechanical conditions.

\section{Strength properties of rock mass}

In the course of studies it was established that at the upper horizons of mines, in frozen rocks, both the strength of rocks and the stability of their outcrops increases due to the cementing factor of permafrost. The rocks themselves are in the strongest possible natural dry state. In transition areas of frozen rocks to thawed rocks, at technological or seasonal thawing of mine workings, the strength properties of rock mass decrease under the influence of periodic ice thawing at temperature close to $0^{\circ} \mathrm{C}$ [11]. Therefore, it is recommended to determine the strength and deformation properties of rocks differentially when evaluating the geomechanical conditions in the permafrost zone:

- for conditions of constant permafrost zone - in natural-dry state of rocks;

- for conditions of transition rocks to thawed rocks and anthropogenic thawing areas - in water-saturated state, after standard 25 freeze-thaw cycles. Such results will be the closest to production;

- for permanently thawed rock conditions - depending on the actual water inflow, i.e. in naturally dry or water-saturated state.

The transition from strength properties of rocks in the samples to their properties in the rock mass is proposed to be made taking into account the coefficient of structural weakening VNIMI (Kim D.N., 1969) [12], modified for cryogenic conditions by specialists of IRNITU (A.M. Pavlov, L.I. Sosnovsky, etc.) [6]:

$$
K=\frac{1}{0.53\left(l / l_{\text {tr }}+1.175\right)}+0.315+\Delta,
$$

where $l$ - maximum linear size of the estimated outcrop strength, $\mathrm{m} ; l_{t r}$ - average distance between cracks, m; $\Delta$ - differential correction factor [6] subject to the influence of permafrost, being taken in frozen rocks equal to 0.4 , in "seasonal" zones to 0.2 , natural transition zones to 0.1 , thawed rocks and areas of technogenic thawing to 0 .

Using this technique, it is possible to estimate the combined effect of permafrost, cracking, and geometric dimensions of rock outcrops on the strength characteristics of rocks in the permafrost zone. The specified properties of rocks, taking into account formula (1), are offered to be used as boundary conditions in calculations of parameters of underground geotechnologies. 


\section{Initial stress state of the rock mass.}

The field stress measurements at the investigated fields were carried out at different temperature conditions: in stable rocks of permafrost rock mass, in natural transition zones of frozen rocks to thawed rocks, in the most unstable rocks of the technogenic thawed rock mass (Table).

The analysis of measurement results allows us to note the following.

Vertical stresses $\left(\sigma_{v}\right)$ at any temperature conditions correspond to theoretical values from weight of overlying rocks. The ratio of stresses directed horizontally along the strike of veins (i.e. longitudinal) $\left(\sigma_{l}\right)$ to vertical ones, increases from 0.7 (Novo-Shirokinskoye deposit, frozen rocks) to 1.8 (Karalveem deposit, thawed rocks) at the rate of progress in depth and thawing of the rock mass. Transverse (oriented horizontally across the strike of veins) stresses $\sigma_{t r}$ change depending on cryogenic conditions from $0.6 \sigma_{V}$ (Kedrovskoe deposit, frozen rocks) to $2.4 \sigma_{V}$ (Irokinda deposit, thawed rocks). The growth of horizontal stresses, with the transition from frozen to thawed rock, and the prevalence of transverse stresses over vertical and longitudinal ones, is a constant trend for all permafrost deposits. Such an increase in horizontal stresses with an increase in the temperature of the rock mass can be related to the fact that in the process of thawing of the rocks the tectonic cracks open and begin to more fully affect the initial stresses. The spread of horizontal stress coefficients within the same temperature zone, at different deposits, is obviously connected with the influence of surface topography (in frozen rocks of the upper horizons) and the difference in tectonic structures of rock masses.

Table 1. Initial stresses of gold deposits at different temperature conditions of rock masses

\begin{tabular}{|c|c|c|c|c|c|c|}
\hline \multirow{3}{*}{$\begin{array}{l}\text { Temperature } \\
\text { zone of mine }\end{array}$} & \multirow{3}{*}{$\begin{array}{l}\text { Rocks } \\
\text { temper- } \\
\text { ature }\end{array}$} & \multirow{3}{*}{ Deposit } & \multirow{3}{*}{$\begin{array}{c}\text { Depth of } \\
\text { observation } \\
\text { stations, m }\end{array}$} & \multicolumn{3}{|c|}{ Initial stresses, $\mathrm{MPa}$} \\
\hline & & & & \multirow[b]{2}{*}{ vertical } & \multicolumn{2}{|c|}{ horizontal } \\
\hline & & & & & $\begin{array}{l}\text { longitu- } \\
\text { dinal }\end{array}$ & ransverse \\
\hline \multirow{7}{*}{$\begin{array}{l}\text { Permafrost } \\
\text { rocks }\end{array}$} & \multirow{7}{*}{$<-1$} & Mayskoye & 120 & $-4.3 \pm 0.3$ & $-3.7 \pm 0.4$ & $-4.3 \pm 0.5$ \\
\hline & & Barun-Holba & 120 & $-2.6 \pm 0.7$ & $-3.3 \pm 0.7$ & $-2.4 \pm 0.4$ \\
\hline & & $\begin{array}{c}\text { Kone- } \\
\text { vinskoye }\end{array}$ & $180-200$ & $-5.4 \pm 0.6$ & $-6.6 \pm 1.9$ & $-4.3 \pm 0.5$ \\
\hline & & Irokinda & 200 & $-7.4 \pm 0.9$ & $-9.3 \pm 1.4$ & $-8.6 \pm 1.8$ \\
\hline & & $\begin{array}{c}\text { Novo- } \\
\text { Shi- } \\
\text { rokinskoye }\end{array}$ & 220 & $-6.7 \pm 0.3$ & $-4.4 \pm 0.4$ & $-5.4 \pm 0.6$ \\
\hline & & $\begin{array}{l}\text { Kedrovsko- } \\
\text { ye }\end{array}$ & 300 & $-8.3 \pm 2.1$ & $-11.6 \pm 3.8$ & $-4.9 \pm 1.0$ \\
\hline & & Barun-Holba & 420 & $-11.6 \pm 1.5$ & $-14.2 \pm 5.2$ & $-13.4 \pm 1.2$ \\
\hline \multirow{3}{*}{$\begin{array}{l}\text { Natural transi- } \\
\text { tion zone of } \\
\text { frozen rocks to } \\
\text { thawed rocks }\end{array}$} & \multirow{3}{*}{$-1 . .+0.5$} & Irokinda & 250 & $-6.6 \pm 0.5$ & $-5.9 \pm 0.4$ & $-10.8 \pm 1.2$ \\
\hline & & $\begin{array}{c}\text { Kone- } \\
\text { vinskoye }\end{array}$ & 300 & $-8.4 \pm 1.2$ & $-10.9 \pm 1.7$ & $-12.5 \pm 1.4$ \\
\hline & & Zun-Holba & 380 & $-11.0 \pm 2.1$ & $-16.6 \pm 1.8$ & $-14.6 \pm 5.0$ \\
\hline $\begin{array}{c}\text { Thawing rocks } \\
\text { due to technical } \\
\text { equipment }\end{array}$ & $>+0.5$ & Irokinda & 250 & $-6.7 \pm 2.3$ & $-9.4 \pm 3.0$ & $-13.5 \pm 3.0$ \\
\hline \multirow{4}{*}{$\begin{array}{l}\text { Natural thawing } \\
\text { rocks }\end{array}$} & \multirow{4}{*}{$>+0.5$} & $\begin{array}{c}\text { Kedrovsko- } \\
\text { ye }\end{array}$ & 400 & $-10.3 \pm 1.1$ & $-15.3 \pm 0.9$ & $-19.9 \pm 4.3$ \\
\hline & & Irokinda & 410 & $-11.6 \pm 3.7$ & $-17.5 \pm 5.1$ & $-27.3 \pm 8.8$ \\
\hline & & Karalveem & 510 & $-15.2 \pm 1.6$ & $-27.7 \pm 4.4$ & $-22.5 \pm 4.3$ \\
\hline & & Zun-Holba & $860-940$ & $-25.3 \pm 2.1$ & $-26.0 \pm 3.0$ & $-42.7 \pm 3.5$ \\
\hline
\end{tabular}

The analysis of tectonic components of initial stresses allows noting that vertical stresses are characterized by actions of gravitational forces only, and their tectonic component is very small, being in a range - $0.7 \ldots 0.1 \mathrm{MPa}$ and not exceeding an error of 
calculation of stresses. Horizontal longitudinal and transverse stresses have both gravitational and tectonic components. The tectonic component of horizontal stresses increases when the peripheral rock mass is thawed from $-3.1 \ldots-4.7 \mathrm{MPa}$ in the permafrost rock mass to $-5.1 \ldots-8.4 \mathrm{MPa}$ in the transition zones and to $-12.9 \ldots-16.3 \mathrm{MPa}$ in completely thawed rocks. Thus, the influence of tectonic disturbance on the natural stress-deformed state of the rock mass at its thawing increases, reaching the maximum in a completely thawed rock mass.

It was found that during the technogenic thawing of the peripheral rock mass the measured horizontal stresses are 1.4-2 times higher than the vertical ones. This distribution of stresses is close to the completely thawed rock mass. However, it is known that the depth of technological thawing in the peripheral rock mass of mine workings does not exceed $2 \mathrm{~m}$ [1]. The rest of the rock mass in the thawing zone remains frozen. It is evident that the initial stresses measured by slot unloading in the areas of technogenic thawing rocks cannot be called natural because the cutting depth of the slot does not exceed the layer of thawed rocks. They will be secondary in relation to natural rocks. However, for engineering calculations of the stability of the mine workings and pillars in the thawing zones, the regularities of distribution of initial stresses in the thawed rocks can be used.

On the basis of the measurement results, the authors have proposed the average dependencies of the distribution of initial stresses in the rock masses of vein gold deposits differentiated by the temperature conditions of rocks:

- In permafrost rocks

$$
\sigma_{v}=-\gamma H-0.3 ; \sigma_{l}=-\frac{\mu}{1-\mu} \cdot \gamma H-5.3 ; \sigma_{t r}=-\frac{\mu}{1-\mu} \cdot \gamma H-3.9 \text {, }
$$

- In natural transition zones of frozen rocks to thawed rocks

$$
\sigma_{v}=-\gamma H-0.1 ; \quad \sigma_{l}=-\frac{\mu}{1-\mu} \cdot \gamma H-7.3 ; \quad \sigma_{t r}=-\frac{\mu}{1-\mu} \cdot \gamma H-8.8,
$$

- In thawed rocks and rocks thawed due to technical equipment

$$
\sigma_{v}=-\gamma H+0.1 ; \quad \sigma_{l}=-\frac{\mu}{1-\mu} \cdot \gamma H-12.6 ; \sigma_{t r}=-\frac{\mu}{1-\mu} \cdot \gamma H-19.4 \text {. }
$$

\section{Conclusions}

When evaluating the geomechanical conditions of deposits located in the permafrost zone, the temperature zoning of the rock mass is of great importance.

The most favorable geomechanical conditions will be observed in permafrost rocks. In frozen rocks, the initial stresses are close to the hydrostatic ones. Due to the cementing factor of the ice that fills the cracks, mine workings and pillars are the most stable.

The most unfavorable geomechanical conditions will be characterized by transition areas of rocks, for natural or technogenic reasons subject to periodic thawing and freezing. The increased gravitational and tectonic stresses act in the transition zones of frozen rocks to thawed rocks. Constant changes in the phase state of water in cracks and rock pores strengthen the processes of destruction of the peripheral rock mass.

The established dependencies of initial stress distribution in different cryolithic conditions (2-4) are proposed to be used as boundary conditions in engineering calculations of structural elements of development systems at the design and initial operation stages of vein gold deposits located in the permafrost zone.

In order to increase the stability of mine workings and pillars in frozen rocks, it is recommended to take measures to prevent the thawing of mine air and peripheral rock mass 
from the action of wellhead ventilation and mining equipment: the thermal insulation of mine walls, the use of electric transport, the regulation of the temperature of air supplied to the mine workings.

\section{References}

1. E. L. Sosnovskaia, A. N. Avdeev, Mining J, 5, 21 (2019)

2. A. M. Pavlov, Geology and Exploration of Ore Deposits, 40, 53 (2012)

3. A. M. Pavlov, Improvement of the technology of the underground development of the gold vein deposits IrSTU Publishing House (2013)

4. D. L. Cluff, V. N. Kazakidis, Proceedings of the 10th International Symposium on Cold Regions Development, Alaska, 175 (1994)

5. G. Kight, M. Harris, B. Gorski, J. E. Udd, Frozen backfill research for Canadian mines, 21 (Canada Centre for Mineral and Energy Technology, Canada, 1994)

6. A. M. Pavlov, Determination of parameters of stable pillars and outcrops at mining the inclined veins in cryogenic zones under conditions of Irokinda gold deposit, Mining Information and Analytical Bulletin, 10, 21 (Gornaya kniga, Moscow, 2014)

7. Yu. M. Semenov, Temperature conditions of rock mass in permafrost zone at Irokinda mine, Problems of development of mineral base of East Siberia: collected scientific works, 228 (IrSTU Publishing house, Irkutsk, 2009)

8. The ISRM Suggested Methods for Rock Characterization, Testing and Monitoring: 2007-2014. Under the editorship of R. Ulusay, Springer International Publishing Switzerland, Cham. 293 (2015)

9. N. P. Vlokh, Rock stresses control at the underground mines 208 (Nedra, Moscow, 1994)

10. E. L. Sosnovskaia, A. N. Avdeev, Mining Information and Analytical Bulletin, 3-1, $208(2020)$

11. A. N. Avdeev, E. L. Sosnovskaia, A. Yu. Bolotnev, D. Batzhargal, Proceedings of the Siberian Branch of the Earth Sciences Section of the Russian Academy of Natural Sciences. Geology, exploration and exploitation of ore deposits, 42, 240 (2019)

12. Kim D. N., Rock pressure, rock displacement and methods of the surveying works: Collection of scientific articles, edited by A. A. Bityutsky; Rail-Building Engineering Center. 72. L.: VNIMI, 568-585 (2007) 